metotrexato han evidenciado utilidad, sobre todo cuando además de la afectación de la columna vertebral hay inflamación en las articulaciones periféricas (1). En ésta enfermedad el infliximab en monoterapia a dosis de $5 \mathrm{mg} / \mathrm{kg}$ administrado en las semanas 0,2 y 6 ha resultado eficaz en comparación al placebo; así el 57\% de los pacientes tratados con éste fármaco tuvo al menos una reducción del $50 \%$ del valor basal en la puntuación de BASDAI, comparado con el $9 \%$ de los tratados con placebo. La mejoría se observó en la semana 2 y se mantuvo hasta la 54 (2).

La evaluación de las lesiones de la columna vertebral evidenciadas por resonancia magnética han mostrado mejoría de las lesiones agudas y ausencia de progresión de las crónicas a los 3 meses de iniciado el tratamiento con infliximab (3).

Los efectos adversos que se han comunicado tras la utilización de éste fármaco han sido: infecciones, incluyendo la tuberculosis y sepsis, tumores, como los linfomas, anemia y pancitopenia, enfermedades desmielinizantes, neuropatía, empeoramiento de la insuficiencia cardiaca congestiva, aparición de anticuerpos y reacciones a la infusión y de hipersensibilidad (1).

Por su escasa frecuencia presentamos un caso de infarto en relación con la administración del infliximab.

Varón de 41 años de edad, diagnosticado de espondilitis anquilosante. Había seguido tratamiento de modo irregular con sulfasalazina, sin mejoría evidente. Refería dolor cervical de perfil inflamatorio y coxalgia izquierda, así como dolor en el hombro izquierdo, rigidez matutina de una hora de duración y parestesias en la mano derecha de predominio nocturno. A la exploración presentaba derrame en la rodilla derecha, dolor a la movilización de ambas caderas, con limitación en todos los planos y dolor a la movilización del hombro izquierdo.

En el laboratorio destacaba una VSG de $80 \mathrm{~mm} /$ hora y una PCR de $39 \mathrm{mg} / \mathrm{L}$.

Debido a estos factores de mal pronóstico, se decidió iniciar tratamiento con infliximab, siguiendo la pauta habitual.

Mientras se estaba procediendo a la $18^{\mathrm{a}}$ administración del fármaco, sin haber presentado previamente ninguna complicación, a los pocos minutos de iniciada la infusión denotó un cuado de dolor precordial irradiado al brazo izquierdo, de características isquémicas, acompañado de sudoración profusa. Se suspendió la infusión y se realizó un ECG que mostró elevación del ST en la cara anterior.

La CPK ( creatinkinasa) ascendió hasta un valor máximo de 317 U/1 y la Troponina I de 1,42 (normal hasta 0,20).

Se inició tratamiento con nitroglicerina en perfusión, cediendo el cuadro doloroso. Posteriormente se realizó coronariografía, objetivando arterias coronarias sin lesiones significativas.

La Sociedad Española de Reumatología puso en marcha en el 2001 una base de datos para el registro de los efectos adversos observados por el tratamiento de los agentes biológicos en las enfermedades reumáticas. Tras más de 4100 enfermos tratados, la mayoría con infliximab $(72 \%)$, seguido de etarnecept $(24 \%)$, se registraron efectos adversos en 1228 casos, predominaban las infecciones $(38 \%)$, seguido de reacciones a la infusión (24\%). Se presentaron problemas cardiovasculares en 79 casos, de los que destacamos insuficiencia cardiaca en 14, infarto de miocardio en 13, trastornos cerebrovasculares en $10 \mathrm{y}$ angina en cinco casos (4).

Dado que en el infarto de miocardio se han encontrado niveles elevados de TNF-alfa, los fármacos que reducen los niveles de TNF-alfa, parecerían prometedores(5).

También se ha examinado si la inhibición de la producción de citoquinas secundaria a la inhibición de macrófagos, sería eficaz en mejorar la función cardiaca tras un infarto agudo de miocardio; observándose una reducción de los niveles de TNF-alfa, pero sin una mejoría de la función cardiaca e incluso existiendo un aumento de la mortalidad (6).

Tras el tratamiento con infliximab se ha observado una disminución del HDL-colesterol y fenómenos de vasoconstricción arterial (7).
Se deduce que los anti-TNF pueden presentar dos efectos, uno agudo con disminución de la luz vascular y que podría justificar el cuadro anginoso de nuestro paciente y otro crónico a largo plazo, por disminución de las HDL-colesterol con incremento del riesgo cardiovascular.

El elevado costo y la posible aparición de efectos adversos potencialmente graves e incluso letales, como los problemas cardiovasculares, nos obligará a realizar una selección muy estricta de los enfermos incluidos para tratamiento y a efectuar un seguimiento muy estrecho de los enfermos tratados con los agentes anti-TNF.

S. Casallo Blanco, A. Aragón Díez, F. Marcos Sánchez, M. A. Cantalejo Moreira, D. Joya Seijo, C. Vicente Martín

Servicio de Medicina Interna. Hospital Nuestra Señora del Prado. Talavera de la Reina. Toledo

1. Mullero Mendoza J, Vera Mendoza M, Infliximab y Etarnecept hoy Información terapéutica del Sistema Nacional de Salud. 2003; 27: 168174.

2. Braun J, Brandt J, Listing J. Treatment of active ankylosing spondylitis with infliximab: a randomised therapy controlled multicentre study. Lancet 2002; 359: 1126-1136.

3. Targan SR, Hanauser SB, Van Denventer SJ, Mayer L. A short-term study of chimeric monoclonal antibody cA2 to tumor necrosis factor alpha for Crohns`s disease. Crohns `s disease cA2 Study Group. N Engl J Med 1997; 337: 1029-1035.

4. Comité Científico de BIODASER. Registro español de acontecimientos adversos de terapias biológicas en enfermedades reumáticas. Rev Esp Reumatol 2004; 31: 479-495.

5. Sugano M, Tsuchida K, Hata T, Makino N. In vivo transfers of soluble TNF-alpha receptor 1 gene improve cardiac function and reduces infarct size after myocardial infarction in rats. Faseb J 2004; 18:911-913.

6. Kherani AR, Moss GW, Zhou H, Gu A, Zhang G, Schulman AR, et al. Macrophage inhibitor sema pimod reduces necrosis factor alpha in myocardium in a rat model of ischemic heart failure. J Cardiovasc Pharmacol 2004; 44: 665-671.

7. Irace C, Mancuso G, Fiaschi E, Madia A, Sesti G, Gnasso A. Effect of anti-TNF-alpha therapy on arterial diameter and wall shear stress and HDL-cholesterol. Atherosclerosis 2004; 177: 113-118.

Papulosis linfomatoide: caso clínico y revisión de la literatura

\section{Sr. Director:}

La papulosis linfomatoide (PL) es una rara enfermedad cutánea crónica recurrente, y de etiología desconocida. La PL se incluye según la Organización Mundial de la Salud(OMS) en el grupo de las enfermedades linfoproliferativas cutáneas primarias de células T CD30 positivas, junto al linfoma cutáneo anaplásico de células grandes y las lesiones borderline. Se trata de un grupo de enfermedades que surgen a partir de células T CD30 positivas activadas y/o transformadas (1), con características clínicas e histológicas superponibles, y que pueden coexistir en un mismo paciente. La PL es más propia de adultos y ancianos, con predominio en el sexo masculino. El curso clínico suele ser prolongado (varios años) y generalmente benigno; aunque el 10-20\% progresan hacia linfomas (linfoma Hodgkin, micosis fungoide y/o linfoma anaplásico $\mathrm{T}$ de células grandes) (2). La PL se caracteriza por la presencia de lesiones exclusivamente cutáneas (pápulas y/o nódulos) recurrentes, 
que suelen regresar espontáneamente en 2-6 semanas. La afectación extracutánea es propia de los casos que progresan a linfomas. La anatomía patológica de estas lesiones muestran un infiltración dérmica por linfocitos $\mathrm{T}$ atípicos junto a un número variable de células inflamatorias (neutrófilos, eosinófilos, macrófagos...). Los linfocitos $\mathrm{T}$ atípicos pueden presentar dos morfologías diferentes: células con núcleo cerebriforme (como en la micosis fungoide) y células Reed-Stenberg-like (como en el linfoma Hodgkin). Se distinguen tres subtipos de papulosis linfomatoide. El subtipo A se caracteriza por un predominio de células Reed-Stenberg-like y numerosas células inflamatorias, mientras que en el subtipo B hay un predominio de células cerebriformes. Estas dos lesiones pueden coexistir en un mismo paciente. El subtipo $\mathrm{C}$ es una lesión borderline con histología de un linfoma, pero con un comportamiento clínico propio de una PL. Las células T atípicas expresan CD4 y CD30 positivas, siendo CD2, CD5, CD8 (3) y proteína ALK-1 negativos. En el $50 \%$ de los casos existe reordenamiento de los genes de TCR ( más propio de las lesiones B) $(4,5)$, siendo la traslocación (2;5) negativa (6).

Presentamos el caso clínico de una transformación de una PL hacia un linfoma $\mathrm{T}$ anaplásico de células grandes tras una larga evolución:

Varón de 45 años, con alopecia universal, que a partir de los 30 años de edad comienza a presentar lesiones cutáneas papulosas rojizas no pruriginosas, que regresan espontáneamente en 23 semanas, de localización preferentemente en cara y tronco, estando asintomático y con una exploración física anodina. Se realiza biopsia de una de las lesiones cutáneas a los 35 años, presentando un infiltrado perivascular dérmico situado en zonas superficiales y profundas, pero también en zonas perifoliculares, constituido por células linfoides y células reactivas fundamentalmente eosinófilos. En el inmunofenotipo destacaba CD30+/ CD45+/EMA-/ALK-1- compatible con una Papulosis Linfomatoide tipo A. Se realiza estudio de extensión con TC toraco-abdominal, biopsia de médula ósea y analíticas siendo negativo. Se decide vigilancia estrecha del paciente. Tras 7 años de seguimiento el paciente presenta una adenopatía laterocervical derecho y un nódulo frontal violáceo. Se realiza un nuevo estudio de extensión que resulta negativo; y se decide continuar con la vigilancia estrecha. Dos años después el paciente presenta un rápido crecimiento de la adenopatía, presentando un conglomerado adenopático de $6 \times 6 \times 5 \mathrm{~cm}$ en región parotídea derecha y supraclaviculares bilaterales y un nódulo violáceo frontal de $6 \mathrm{~cm}$. Se realiza estudio de extensión que es negativo, con una gammagrafía con Galio 67 que capta sólo en región parotídea derecha y frontal, y la biopsia ganglionar revela un infiltrado celular, donde destaca la presencia de células linfoide atípicas de gran talla, de núcleo grande con varios nucleolos prominentes agrupadas entre sí; y áreas confluyentes de necrosis coagulativa. Las células neoplásicas son CD30+/ CD45+/ CD3+/ EMA+/ bcl-2+/ ALK-1 -/CD4-/CD8-/CD20-/CD68-; con el diagnóstico de linfoma $\mathrm{T}$ anaplásico de células grandes. Se inicia entonces quimioterapia con esquema CHOP, presentando una aparente remisión tras 6 ciclos.

Nueve meses después vuelve a presentar una recidiva con presencia de múltiples adenopatías mediastínicas, cervicales, axilares e inguinales en la TC. Inicia una segunda línea con Fludarabina que es retirada tras 2 ciclos al objetivarse nueva progresión de la enfermedad. Tras 6 ciclos de la tercera línea de quimioterapia con ESHAP el paciente presenta nueva remisión aparente.

\section{P. Khosravi Shahi}

Servicio de Oncología Médica. Hospital General Universitario Gregorio Marañón. Madrid
1. Willemze R, Kerl H, Sterry W, Berti E, Cerroni L, Chimenti S et al. EORTC classification for primary cutaneous lymphomas: a proposal from Cutaneous Lymphoma Study Group of the European Organization for Research and Treatment of Cancer.Blood 1997; 90: 354-71.

2. Bekkenk MW, Huelen FA, Voorst Vader PC, Heule F, Geerts ML, van Vloten WA et al. Primary and secondary cutaneous CD30(+) lymphoproliferative disorders: a report from the Dutch Cutaneous Lymphoma Group on the long-term follow-up data of 219 patients and guidelines for diagnosis and treatmment. Blood 2000; 95: 3653-61.

3. Kadin M, Nasu K, Sako D, Said J, Vonderheid E. Lymphomatoid papulosis. A cutaneous proliferation of activated helper $\mathrm{T}$ cells expressing Hodgkin's disease-associated antigens. Am J Pathol 1985; 119: 315-25.

4. Weis LM, Wood GS, Trela M, Warnke RA, Sklar J. Clonal T-cell populations in lymphomatoid papulosis. Evidence of a lymphoproliferartive origin for a clinically benign disease. N Engl J Med 1986; 315: 475-79.

5. Chott A, Vonderheid EC, Olbright S, Miao NN, Balk SP, Kadin M. The dominant $\mathrm{T}$ cell clone is present in multiple regresing skin lesions and associated $\mathrm{T}$ cell lymphomas of patients with lymphomatoid papulosis. J Invest Dermatol 1996; 106: 696-700.

6. Beylot-Barry M, Groppi A, Vergier B, Pulford K, Merlio JP. Characterization of $\mathrm{t}(2 ; 5)$ reciprocal transcripts and genomic breakpoints in CD30+ cutaneous lymphoproliferations. Blood 1998; 91: 4668-76.

\section{Evolución de la enfermedad de Graves tras tratamiento con radioyodo}

\section{Sr. Director.}

El tratamiento de la hiperfuncion tiroidea con I-131 fue utilizado por primera vez en 1941 y desde entonces, es empleado como terapia de primera línea, en el tratamiento de la Enfermedad de Graves (EG) que recidiva tras la utilización de antitiroideos de síntesis. Es considerado una terapia eficaz, de fácil administración y bajo coste $(1,2)$. El objetivo del estudio es conocer la evolución de la Enfermedad de Graves tratada con I131.

Se estudia prospectivamente la evolución de la función tiroidea en 32 pacientes diagnosticados de EG que recidivaron tras un tratamiento de 20,25 $\pm 3,6$ meses, con antitiroideos de síntesis. Se analizan los siguientes parámetros, edad, sexo, volumen tiroideo, dosis de radioyodo (ajustada a captación a las 24 h). La función tiroidea previa al radioyodo se normalizó con metimazol (5-20 mg. día). Para el análisis estadístico de empleó el G-Stat software, versión 1.0 (e-biometrica.com, GlaxoSmithKleinEspaña).

De los 32 pacientes estudiados 22 fueron mujeres $(68,7 \%)$ y 10 varones $(31,2 \%)$. Con una edad media de $38,3 \pm 11,7$ años (19-69 años). Los pacientes fueron controlados durante 34,3 \pm 15 meses (12-72 meses). La dosis total de I-131 empleada fue de $22,5 \pm 12,9 \mathrm{mCi}$. Las mujeres recibieron $18,5 \pm 1,7 \mathrm{mCi}$ y los varones $30,8 \pm 5,7 \mathrm{mCi}(\mathrm{p}<0,01)$. Un $37,9 \%$ de los pacientes precisaron de una segunda dosis por nueva recidiva de su hipertiroidismo, siendo el intervalo entre ambas dosis de 8-24 meses. Un 82,4\% desarrolló hipotiroidismo entre los 5,3 \pm 4,8 meses de la última dosis de radioyodo administrada. El hipotiroidismo se relacionó únicamente con el número y cantidad de dosis administrada $(\mathrm{p}<0,001)$.

A pesar de que el tratamiento con I-131 en pacientes con enfermedad de Graves es seguro y eficaz, está contraindicado en embarazadas, lactancia y niños (3). La utilización de antitiroideos de síntesis previos al tratamiento con I-131 y sus efectos sobre la eficacia del mismo es un hecha bien conocido, nosotros empleamos el metimazol el cuál no ha demostrados alteración en la efectividad del radioyodo a diferencia del propiltiouracilo (4). 